\title{
PortuglishQuizlet: jogo educacional na aprendizagem de língua inglesa
}

\section{PortuglishQuizlet: educational game in English language learning}

\author{
Karlucy Farias de Sousa ${ }^{1}$ \\ Francisco Rodrigues de Lima Neto² \\ Nukácia Meyre Silva Araújo ${ }^{3}$
}

\begin{abstract}
Resumo
Considerando as dificuldades que os discentes do Instituto Federal de Educação, Ciência e Tecnologia do Ceará - Campus Limoeiro do Norte enfrentam quando estão cursando a disciplina de "Inglês Instrumental" ou "Inglês Técnico" devido à falta de conhecimentos acerca das funções das classes gramaticais da Língua Portuguesa, esta narrativa de ensino tem o objetivo de apresentar o desenvolvimento de um jogo educacional, PortuglishQuizlet, que foi utilizado como um recurso didático para auxiliar na aprendizagem de língua inglesa, em uma tentativa de suprir a deficiência em conhecimentos linguísticos do português. Durante a elaboração do jogo, definimos as regras, a quantidade de cartas e as classes gramaticais que seriam usadas: artigos, substantivos, pronomes e preposições. Ao final do semestre letivo, os aprendizes foram convidados a preencher um formulário sobre o PortuglishQuizlet. Observou-se que $86 \%$ gostaram de jogar o PortuglishQuizlet e citaram os seguintes motivos: era uma ferramenta fácil de manusear, interativa e dinâmica, o que proporcionou aprimoramento do vocabulário; $60 \%$ relataram que gostaram de jogar devido a sua praticidade. Podemos concluir que o ensino de inglês com 0 auxílio do PortuglishQuizlet parece ter beneficiado os discentes.
\end{abstract}

Palavras-chave: Jogo Educacional. Aprendizagem de Inglês. Classes gramaticais.

\begin{abstract}
Considering the difficulties that students from the Federal Institute of Education, Science and Technology of Ceará - Campus Limoeiro do Norte face when they are studying the academic subjects related to English for Specific Purposes, mainly due to the lack of knowledge about the functions of the grammatical classes of Brazilian Portuguese, this teaching narrative aims at presenting the development of an educational game, PortuglishQuizlet, which was used as a didactic resource to help in the English language learning, in an attempt to address the lack of linguistic knowledge of Brazilian Portuguese. During the development of the game, we defined the rules, the number of cards and the grammatical classes that would be used: articles, nouns, pronouns, and prepositions. By the end of the semester, the students were invited to fill in a questionnaire about PortuglishQuizlet. It was observed that $86 \%$ of students enjoyed playing PortuglishQuizlet and cited the following reasons: it was an easy-to-use, interactive, and dynamic tool, which offered vocabulary improvement; $60 \%$ said that they enjoyed playing it because of its practicality. We can conclude that teaching English with the help of PortuglishQuizlet seems to have benefited the students.
\end{abstract}

Keywords: Educational Game. English Learning. Grammatical classes.

\footnotetext{
1 Doutoranda. IFCE. (Instituto Federal de Educação, Ciência e Tecnologia do Ceará, Limoeiro do Norte, Ceará, Brasil). Orcid: https://orcid.org/0000-0003-3967-9324. E-mail: karlucy.farias@ifce.edu.br.

${ }^{2}$ Graduando. IFCE. (Instituto Federal de Educação, Ciência e Tecnologia do Ceará, Limoeiro do Norte, Ceará, Brasil). Orcid: https://orcid.org0000-0001-6190-7309. E-mail: francisco.rodrigues.lima07@aluno.ifce.edu.br.

${ }^{3}$ Doutora. UECE. (Universidade Estadual do Ceará, Fortaleza, Ceará, Brasil). Orcid: https://orcid.org/0000-0003-1951-0417. E-mail: nukacia.araujo@uece.br.
} 


\section{Todo jogo tem um começo!}

Conseguir se comunicar em uma Língua Estrangeira (LE), hoje, é imprescindível em um mundo cada vez mais globalizado, uma vez que estamos lidando com a intensificação das relações comerciais, com o intercâmbio de culturas diversas e com o mercado de trabalho cada vez mais complexo. No entanto, Sousa (2020) destaca que, para atingirmos um nível adequado de proficiência, devemos observar várias etapas, que se estendem desde conhecer a estrutura formal até uma reprodução correta dessa língua, além de considerar que nossa língua materna é possivelmente uma fonte indispensável para uma melhor compreensão da LE que desejamos aprender.

No contexto de ensino das disciplinas de "Inglês Instrumental" e "Inglês Técnico" no Ensino Técnico e Tecnológico do Instituto Federal de Educação, Ciência e Tecnologia do Ceará (IFCE), assim como nos cursos de Licenciatura e Bacharelado do Campus Limoeiro do Norte, percebemos, quando se discutem estratégias relacionadas ao uso do dicionário, que é recomendado que os estudantes ${ }^{4}$ leiam textos, sempre que possível, sem usar o dicionário, considerando que é possível tentar entender o significado de uma palavra através do seu contexto (talvez o leitor não compreenda o significado exato de uma palavra, mas pode entender o suficiente para continuar a leitura) e que a consulta ao dicionário é indicada somente para as palavras imprescindíveis à compreensão, que normalmente são "palavras de conteúdo"; os alunos não parecem saber ao que se está fazendo referência. Quando é sugerido que eles evitem pesquisar no dicionário "palavras de função", percebe-se, mais uma vez, que eles não sabem do que se trata. Em nome da clareza, é explicado a eles que "palavras de conteúdo semântico" são substantivos, verbos, adjetivos e advérbios; por sua vez, "palavras de função gramatical" são artigos, preposições e conjunções. Quando os aprendizes são questionados se ainda há alguma dúvida, recorrentemente, algum costuma indagar sobre a diferença entre uma conjunção e uma preposição, ou entre um adjetivo e um advérbio.

Partindo do princípio de que todos os alunos do Ensino Superior já concluíram o Ensino Médio, assim como vários alunos dos Cursos Técnicos Subsequentes, torna-se evidente para nós que, embora esses aprendizes tenham estudado português por cerca de doze anos de suas vidas escolares, as funções das classes gramaticais não são algo que eles compreendem apropriadamente. Essa dificuldade continua atrapalhando-os em outros conteúdos durante o semestre letivo: por exemplo, quando grupos

\footnotetext{
${ }^{4}$ Os termos "discentes", "alunos", "estudantes", "aprendizes" e "educandos" são usados de forma intercambiável neste texto.
} 
nominais em inglês são estudados. Ressalta-se que é preciso ter alguns cuidados quando traduzimos esses grupos nominais para o português, uma vez que a ordem seguida pelas palavras é diferente. $\mathrm{Na}$ Língua Portuguesa, os modificadores (pronomes, adjetivos, advérbios e até substantivos) geralmente aparecem após o substantivo, enquanto, na Língua Inglesa, os modificadores aparecem antes do substantivo.

Tendo isso em vista, Costa e Lima (2014) argumentam que jogos educacionais promovem mais interesse por parte dos alunos, o que implica em resultados positivos, como a mudança de postura dos alunos em relação à aprendizagem do inglês. Vale acrescentar que, devido à sua grande versatilidade, dependendo da finalidade, os jogos educacionais podem auxiliar no ensino de estruturas gramaticais, na ampliação de vocabulário, no desenvolvimento da leitura, da escrita, da compreensão, da pronúncia e de qualquer conteúdo, habilidade ou competência necessária ao aprendizado de uma LE. Além disso, os jogos também viabilizam um contexto interativo, o qual beneficia o convívio em sala de aula, promovendo, segundo Silva (2012, p. 12), "um ambiente mais acolhedor".

De acordo com Melo (2005), vários estudos que abordam atividades lúdicas comprovam que um jogo pode contribuir significantemente para o processo de construção do conhecimento do aluno, atuando como um mediador da aprendizagem. Por sua vez, Barbanti (2003) menciona que o jogo é uma forma de competição prazerosa, cujo resultado é determinado por habilidades motoras, estratégias ou chances, empregadas isoladamente ou em combinação.

Nesse contexto, acreditamos que o desenvolvimento de um jogo educacional, com traços de gamificação, pode ser utilizado como um recurso didático e auxiliar na aprendizagem de língua inglesa, suprindo a carência em conhecimentos linguísticos do português. Alves (2014, p. 112) define a gamificação como "a utilização de mecânica, estética e pensamento baseados em games para engajar pessoas, motivar a ação, promover a aprendizagem e resolver problemas". A autora contextualiza que, "com a evolução da sociedade, devido à velocidade dos acontecimentos e com os recursos tecnológicos disponíveis atualmente, as experiências de aprendizagem devem ser cada vez mais inovadoras" (ALVES, 2014, p. 16). Ainda de acordo com a mesma autora, "o que funcionava antes não necessariamente funciona hoje quando o assunto é aprendizagem. É neste cenário que a gamificação se encaixa" (ALVES, 2014, p. 19). Dessa forma, ela argumenta que a gamificação "como estratégia de aprendizagem é uma forma interativa e divertida para o alcance de um objetivo específico e mensurável" (ALVES, 2014, p. 132).

Existem outros jogos que também são utilizados com fins educacionais nas salas de LE, como o Scrabble. 0 jogo consiste em formar palavras em inglês através de peças com letras do alfabeto. Ele 
possui uma boa aceitação, uma vez que dispõe de elementos lúdicos ao processo de ensinoaprendizagem, podendo ser um recurso pedagógico para os professores de Inglês. Para Kishimoto (1996), o jogo não pode ser considerado o fim da aplicação de um conteúdo, mas sim um instrumento que favorece a construção daquele conteúdo didático, por meio da relação do lúdico com as informações.

Contudo, não existe nenhum jogo que trabalhe as dificuldades encontradas na aprendizagem de uma LE causadas pela falta de conhecimento teórico acerca da nossa língua materna, focando em aspectos bastante específicos, como as classes gramaticais. Essa lacuna é a justificativa maior para o desenvolvimento do projeto aqui relatado.

Diante disso, o jogo foi idealizado para ser utilizado pelos alunos regularmente matriculados na disciplina de "Inglês Instrumental" ou "Inglês Técnico", independentemente de estarem no Ensino Técnico ou Tecnológico do IFCE, nos cursos de Licenciatura ou Bacharelado de um campus no interior do estado. Eles poderiam jogar durante as aulas nas quais "classes gramaticais" e "grupos nominais" fossem abordados, além de utilizá-lo nos momentos em que estiverem com maior disponibilidade de tempo (um exemplar do jogo poderia ser disponibilizado na biblioteca do campus). Assim, os estudantes poderiam jogá-lo para revisar o conteúdo, como exemplo.

Quanto à elaboração do jogo, definimos as regras, a quantidade de cartas e as classes gramaticais usadas: artigos, substantivos, pronomes e preposições. Tomamos como base a lista que foi feita com as cem palavras mais comuns em inglês encontradas em textos globalmente, baseada no corpus com bilhões de palavras em inglês da Universidade de Oxford (ENGLISHCLUB.COM, 2020), e preparamos um protótipo inspirado no jogo UNO5.

Na Figura 01, temos o layout que escolhemos para o jogo, que constituiu o verso de todas as cartas; na Figura 02, temos o exemplo de uma carta do grupo dos "Artigos" (parte interna da carta); por sua vez, na Figura 03, temos uma carta do grupo dos "Pronomes":

\footnotetext{
${ }^{5}$ A origem do UNO data de 1971, nos Estados Unidos: Merle Robbins o criou. Com cinquenta anos de uma história de enorme sucesso, 150 milhões de cópias já foram vendidas em mais de 80 países. Além disso, há um aplicativo que viabiliza a realização de partidas on-line, em tempo real, com jogadores de qualquer lugar do mundo. (METROPOLY, 2017). 0 objetivo de um(a) jogador(a) do UNO é ser o(a) primeiro(a) a ficar sem cartas na mão. Para tal, é necessário jogar uma carta de cada vez que corresponda ao número ou cor da carta jogada anteriormente. Quando se tem apenas uma carta na mão, deve-se gritar "UNO".
} 


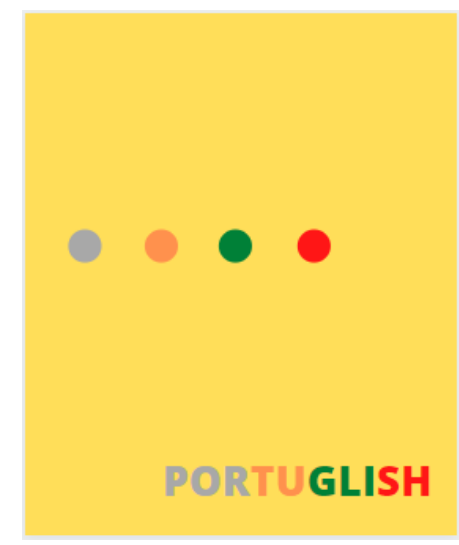

Figura 01: Layout. Fonte: Os autores.

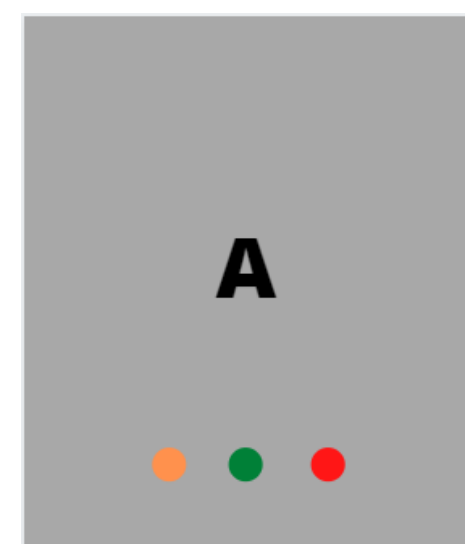

Figura 02: Artigos. Fonte: Os autores.

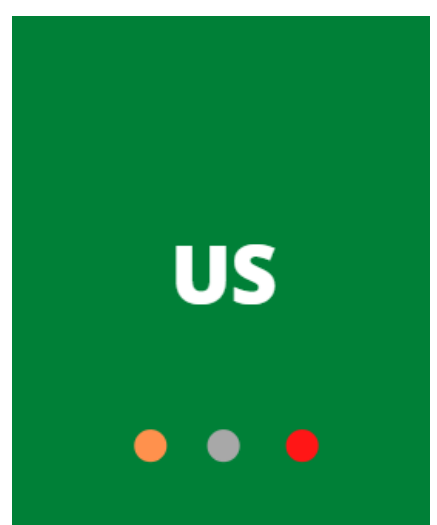

Figura 03: Pronomes. Fonte: Os autores.

Considerando o estado de Emergência em Saúde Pública no Ceará, decorrente do enfrentamento do Coronavírus (SARS-COV-2/COVID-19) e o início do Ensino Remoto Emergencial em março de 2020, os participantes da pesquisa não puderam ir até a instituição, o que inviabilizou a testagem do jogo. Para tentar superar essa dificuldade, como as aulas estão ocorrendo remotamente, adaptamos o jogo e criamos uma versão virtual dele na plataforma Quizlet ${ }^{6}$ (QUIZLET INC, 2020) para poder testar a metodologia que idealizamos com os discentes, como podemos ver nas Figuras 04 e 05:

\footnotetext{
${ }^{6}$ Quizlet é uma ferramenta digital de estudo gratuita desenvolvida pela Quizlet Inc. Criada em janeiro de 2007, esse método interativo de estudos por meio de flashcards surgiu a partir de uma necessidade de seu criador, o norte-americano Andrew Sutherland, que precisava memorizar uma relação de palavras em francês para fazer um quiz sobre vocabulário, o "la quizlette", que posteriormente acabou originando o nome desse Recurso Educacional Digital. Nossa escolha deveu-se às características da ferramenta, que a) tem versão em português; b) tem uma plataforma digital e um aplicativo; c) viabiliza a criação rápida de cartões que podem conter imagens e/ou texto; d) permite pesquisar listas de estudos criadas por outros estudantes e professores (CRESPO; CRESPO, 2020). Destaca-se que é preciso estar on-line para ter acesso a esse recurso.
} 


\section{Quizlet PROFESSOR Página inicial Explicaçōes Suabiblioteca $\vee$ Criar $\vee$}

\section{Portuglish}

$5.0 * \hbar \star \star \star$ lavaliação

JOGO PARA A SALA DE AULA

₹ Live

ESTUDAR

Cartões

C. Aprender

Artigos

$\measuredangle$ Escrever

4) Soletrar

E Avaliar

믐 Combinar

Gravidade

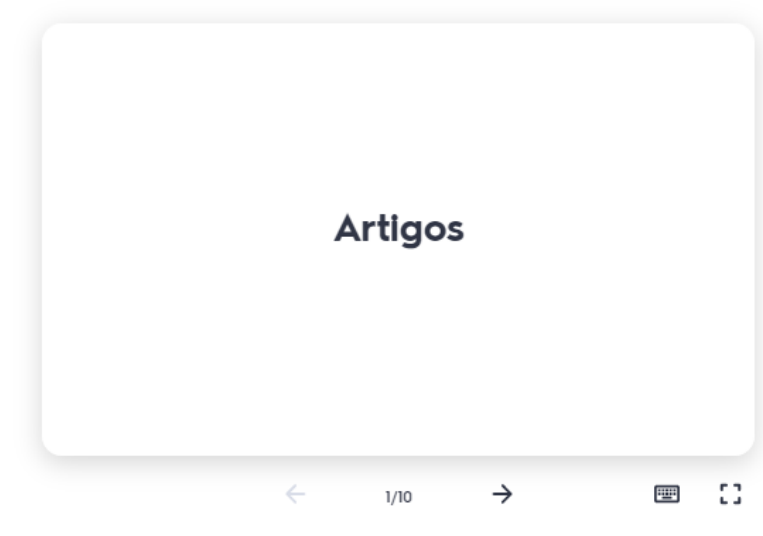

Figura 04: Tela inicial do Portuglish no Quizlet.

Fonte: Os autores.

\section{Quizlet ProfEssor Página inicial Explicaçōes Sua biblioteca $\vee$ Criar $\vee$}

\section{Portuglish}

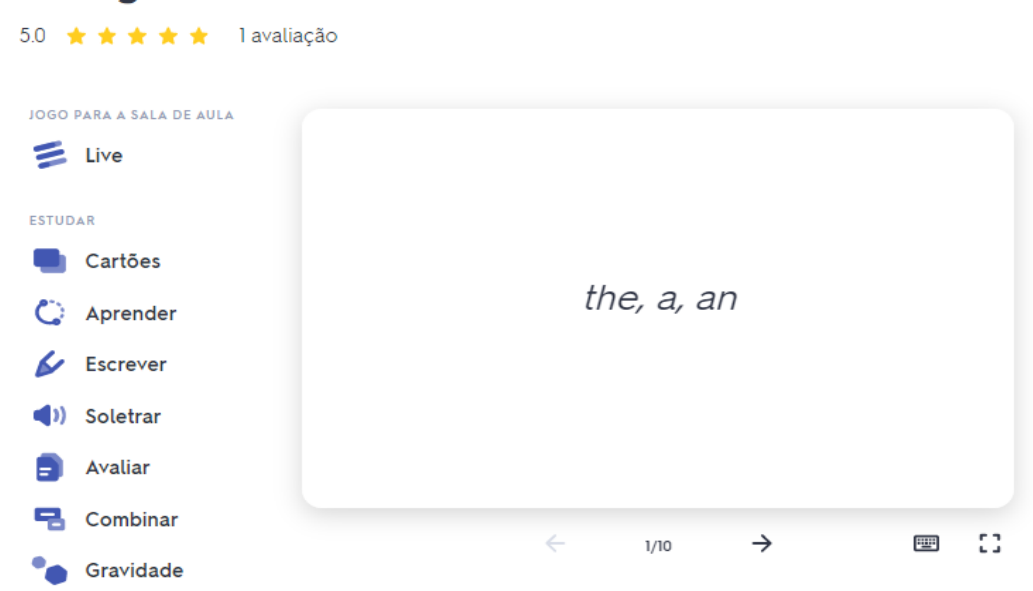

Figura 05: 0 verso do cartão dos Artigos. Fonte: Os autores.

Na próxima seção a seguir, discutiremos os dados que foram identificados através da pesquisa feita com os discentes para avaliar a aceitação do jogo PortuglishQuizlet. 


\section{Avaliar é preciso!}

Após a criação do jogo, um estudo de caso exploratório, com traços descritivos, foi conduzido. Segundo Paiva (2019), essa abordagem metodológica apresenta um objeto específico de estudo único. Por envolver seres humanos, é relevante mencionar que a pesquisa foi submetida à apreciação do Comitê de Ética em Pesquisa do IFCE (CAAE: 44164621.9.0000.5589) e recebeu a aprovação em 14 de abril de 2021.

Na terceira aula do semestre, a docente responsável pela disciplina preparou uma aula sobre as palavras mais comuns da língua inglesa (ENGLISHCLUB.COM, 2020). Após a exposição do conteúdo, a professora apresentou aos discentes o Portuglish Quizlet, mostrando-os como utilizá-lo e sugerindo que eles acessassem, posteriormente, para estudar e/ou revisar o conteúdo. Destacaram-se o uso de dois recursos: a) "Cartões", no qual "cartões digitais são virados ao receber um clique e possuem a finalidade de revisão" (FRANCO, 2018, p. 7) e b) "Combinar", "no qual os usuários devem combinar termos e definições que se encontram espalhados na tela, com tempo cronometrado" (FRANCO, 2018, p. 8).

No final do semestre, após testarem o jogo, os discentes foram convidados a preencher um formulário que apresentava perguntas sobre o Perfil Discente e o PortuglishQuizlet. O questionário foi preparado no Google Forms e compartilhado por e-mail para 225 discentes que se encontravam matriculados na instituição e já haviam finalizado ou estavam cursando o componente curricular "Inglês Instrumental", "Inglês Instrumental l" ou "Inglês Técnico" no semestre letivo de 2020.1, que ocorreu entre os meses de março e novembro de 2020; contudo, somente 35 estudantes participaram. 0 formulário foi disponibilizado por 45 dias e foi reenviado três vezes, a cada quinze dias. Acreditamos que o contexto pandêmico e dificuldades de acesso à internet influenciaram no número de participantes que tivemos. 0 corpus deste estudo foi constituído a partir das respostas dadas pelos sujeitos no questionário que eles foram convidados a preencher. Analisamos quantitativamente as referidas respostas para a análise dos dados. Transformamos em números percentuais os números absolutos que foram encontrados.

No formulário compartilhado com os participantes, a pergunta inicial versava sobre a aceitação deles em participar da pesquisa: todos os trinta e cinco que responderam, aceitaram. A segunda pergunta indagou sobre quais eram os Cursos de Graduação deles: a maioria era do Curso de Tecnologia em Alimentos ou do Curso de Licenciatura em Música, como pode ser visto na Tabela 1: 


\begin{tabular}{ccc}
\hline Cursos & $\mathbf{N}^{7}$ & $\%$ \\
\hline Bacharelado em Nutrição & 01 & $4 \%$ \\
Tecnologia em Alimentos & 15 & $42 \%$ \\
Tecnologia em Saneamento Ambiental & 04 & $12 \%$ \\
Licenciatura em Música & 15 & $42 \%$ \\
\hline Total & 35 & $100 \%$
\end{tabular}

Tabela 1. Cursos de Graduação dos participantes.

Fonte: Os autores.

A terceira questão se referia à idade dos alunos: a maioria estava no intervalo de idade entre 19 e 23 anos, como pode ser verificado na Tabela $2^{8}$ :

\begin{tabular}{ccc}
\hline Faixa etária & N & $\%$ \\
\hline 19 a 23 anos & 18 & $51 \%$ \\
24 a 28 anos & 02 & $6 \%$ \\
29 a 33 anos & 01 & $4 \%$ \\
34 a 38 anos & 06 & $17 \%$ \\
39 a 43 anos & 04 & $11 \%$ \\
49 ou mais & 04 & $11 \%$ \\
\hline Total & 35 & $100 \%$
\end{tabular}

Tabela 2. Idade dos discentes. $^{9}$

Fonte: Os autores.

A questão seguinte questionou com qual sexo os entrevistados se identificavam: três quartos dos participantes eram mulheres, conforme os dados disponibilizados na Tabela 3:

\begin{tabular}{ccc}
\hline Sexo & N & $\%$ \\
\hline Mulheres & 26 & $74 \%$ \\
Homens & 09 & $26 \%$ \\
\hline Total & 35 & $100 \%$
\end{tabular}

Tabela 3. Sexo dos estudantes.

Fonte: Os autores.

${ }^{7}$ Refere-se à quantidade de participantes de cada grupo.

${ }^{8}$ Nenhum dos participantes estava na faixa etária entre 44 e 48 anos.

9 Foi usada a classificação de faixa etária do IBGE. 
A quinta questão tratava sobre o nível de escolaridade dos participantes: seis já haviam concluído o nível técnico, vinte e seis estavam cursando o nível superior e três eram especialistas. $\mathrm{Na}$ sequência, a próxima questão versava sobre o estágio do Curso de Graduação dos discentes: trinta e um afirmaram que estavam cursando e apenas quatro reportaram que já haviam concluído uma graduação. A sétima pergunta questionou se os alunos estavam interessados em aprender inglês: vinte e nove sinalizaram ter muito interesse em aprender. É valido ressaltar que uma das opções vislumbrava a possibilidade de os aprendizes não perceberem a necessidade em aprender a língua inglesa, mas nenhum deles selecionou essa opção, como pode ser visto na Tabela 4:

\begin{tabular}{ccc}
\hline $\begin{array}{c}\text { Interesse em aprender } \\
\text { inglês }\end{array}$ & $\mathbf{N}$ & $\%$ \\
\hline Bastante interesse & 29 & $83 \%$ \\
Pouco interesse & 06 & $17 \%$ \\
Nenhum interesse & 0 & $0 \%$ \\
\hline Total & 35 & $100 \%$ \\
\hline
\end{tabular}

Tabela 4. Interesse dos discentes em aprender inglês.

Fonte: Os autores.

A oitava questão indagava se os estudantes já tinham feito algum curso de inglês antes de cursar uma das disciplinas de língua inglesa ofertadas pelo campus. A maioria indicou que o contato inicial ocorreu quando cursaram o componente curricular; outros indicaram que já tinham feito alguns cursos da referida língua antes, mas de curta duração, como pode ser visto na Tabela 5:

\begin{tabular}{ccc}
\hline Opções & $\mathbf{N}$ & $\%$ \\
\hline Sim & 30 & $86 \%$ \\
Não & 05 & $14 \%$ \\
\hline Total & 35 & $100 \%$
\end{tabular}

Tabela 5. Contato anterior dos alunos com a língua inglesa.

Fonte: Os autores.

A nona pergunta tratava do caso do(a) discente ter feito algum curso de inglês antes e perguntava por quanto tempo: vinte e dois falaram que nunca tinham feito nenhum curso antes e apenas sete afirmaram que já tinham feito (com duração média de um mês a três meses). Por sua vez, a décima questão inquiriu como os participantes definiam o seu nível em inglês. Observamos que mais da metade 
dos discentes classificou seu nível como razoável; contudo, mais de um terço deles consideraram que seu nível era muito ruim/insuficiente, conforme dados apresentados na Tabela 6 :

\begin{tabular}{ccc}
\hline Nível de Inglês & N & $\%$ \\
\hline Excelente & 01 & $3 \%$ \\
Muito bom & 01 & $3 \%$ \\
Razoável & 21 & $60 \%$ \\
Muito ruim/insuficiente & 12 & $34 \%$ \\
\hline Total & 35 & $100 \%$
\end{tabular}

Tabela 6. Percepção pelos participantes de seus respectivos níveis de inglês.

Fonte: Os autores.

A décima primeira pergunta analisou a relevância que os alunos davam a aprender a língua inglesa em relação a sua formação acadêmica: dezesseis responderam que era extremamente importante, quatorze afirmaram que era muito importante. É relevante destacar que nenhum dos participantes selecionou a opção que afirmava que não há importância em aprender a referida língua, como pode ser visto na Tabela 7:

\begin{tabular}{ccc}
\hline Nível de importância de aprender inglês & N & $\%$ \\
\hline Extremamente importante & 16 & $46 \%$ \\
Muito importante & 14 & $40 \%$ \\
Pouco importante & 05 & $14 \%$ \\
Total & 35 & $100 \%$ \\
\hline
\end{tabular}

Tabela 7. Importância atribuída pelos estudantes a aprender inglês. Fonte: Os autores.

Ainda considerando a importância de aprender inglês para a sua formação acadêmica, caso respondesse sim, os participantes precisavam indicar a razão: entre as respostas mencionadas com maior frequência, destacamos as que apontavam que era por se tratar de uma língua universal; logo, era de extrema importância, tanto para o meio acadêmico como para o pessoal (músicas, séries e viagens internacionais).

Na pergunta seguinte, indagou-se se os alunos tinham o costume de usar ferramentas digitais (sites, jogos, aplicativos) para aprender inglês: quase todos afirmaram que sim, como apresentado na Tabela 8: 


\begin{tabular}{ccc}
\hline Opções & $\mathbf{N}$ & $\%$ \\
\hline Sim & 31 & $88 \%$ \\
Não & 04 & $12 \%$ \\
\hline Total & 35 & $100 \%$
\end{tabular}

Tabela 8. Discentes que costumam jogam no celular. Fonte: Os autores.

Se a resposta fosse "sim", os discentes teriam que citar os tipos de jogos que eles jogavam regularmente. Os mais citados foram: Duolingo, Quizlet, Lyrics Training, entre outros.

$\mathrm{Na}$ questão seguinte, questionou-se como foi o primeiro contato dos discentes com 0 PortuglishQuizlet, a maioria falou que foi durante a disciplina de inglês. Na décima sexta questão, os participantes foram indagados se eles gostaram de jogar o PortuglishQuizlet, quase todos gostaram, conforme exposto na Tabela 9:

\begin{tabular}{ccc}
\hline Opções & $\mathbf{N}$ & $\%$ \\
\hline Sim & 30 & $86 \%$ \\
Não & 05 & $14 \%$ \\
\hline Total & 35 & $100 \%$
\end{tabular}

Tabela 09. Participantes que gostaram de jogar PortuglishQuizlet. Fonte: Os autores.

Caso a resposta fosse "sim", questionava-se por quais motivos. Segundo os participantes, o PortuglishQuizlet era simples de manusear, interativo, dinâmico e com um bom aprimoramento do vocabulário, como pode ser visto na Figura 1. 


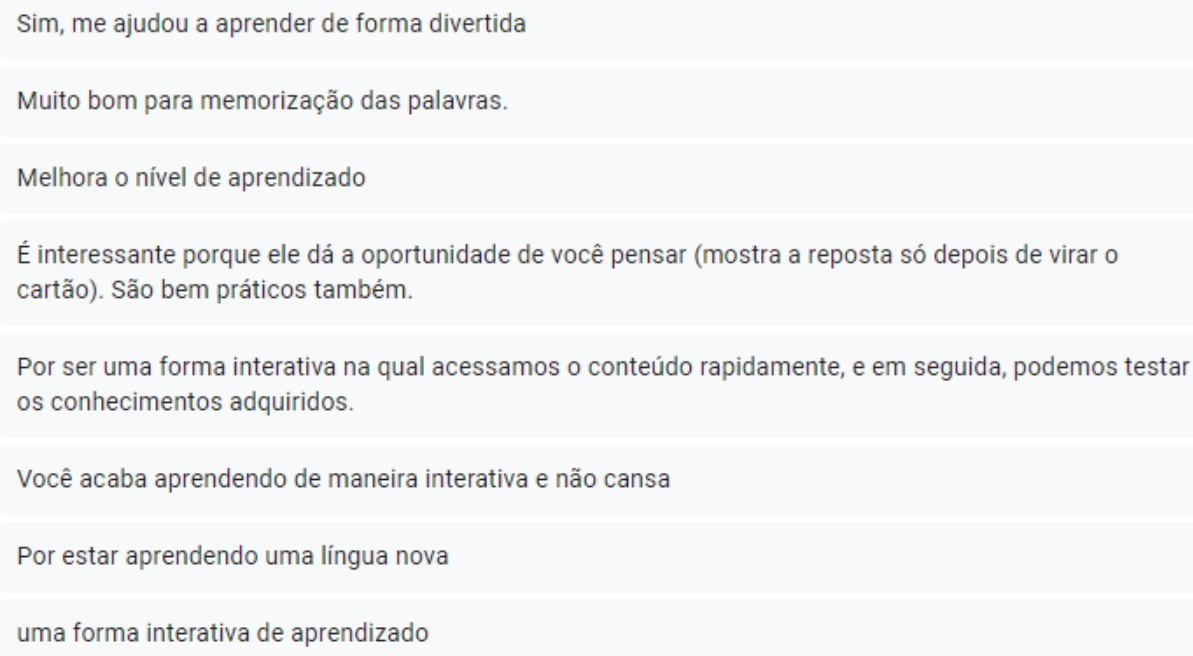

Figura 1. Respostas dos participantes com razões para gostar de jogar o PortuglishQuizlet. Fonte: Os autores.

$\mathrm{Na}$ questão a seguir, os alunos foram questionados se consideravam fácil usar 0 PortuglishQuizlet, a maioria respondeu que sim, como pode ser observado na Tabela 10:

\begin{tabular}{ccc}
\hline Opções & N & $\%$ \\
\hline Sim & 21 & $60 \%$ \\
Não & 14 & $40 \%$ \\
\hline Total & 35 & $100 \%$ \\
\hline
\end{tabular}

Tabela 10. Opinião dos discentes sobre a facilidade de usar o PortuglishQuizlet. Fonte: Os autores.

Como pode ser visto na tabela anterior, vinte e um participantes responderam que 0 PortuglishQuizlet era de fácil manuseio. A seguir, indagou-se aos alunos o que eles mais tinham gostado em jogar o Portuglish Quizlet: entre as respostas, destacaram que era bem prático; não dava as respostas logo; a forma didática que ele funciona; a forma como é apresentado (layout) e a objetividade nas perguntas e respostas. Questionou-se o que eles menos gostavam no PortuglishQuizlet e o porquê: alguns relataram que na parte de combinar as posições o jogo ficava meio confuso; tinha um tempo curto; pouca variedade e sua repetitividade.

A questão seguinte indagou aos discentes o que eles tinham aprendido com o Portuglish Quizlet: entre as respostas citadas, a parte da gramática; alguns artigos; substantivos, pronomes e verbos e as noções básicas do inglês. Indagou-se ainda acerca da quantidade de dias semanalmente que os 
participantes dedicavam ao jogo: a maioria comentou que era entre um e dois dias por semana, como exposto na Tabela 11.

\begin{tabular}{ccc}
\hline Opções & $\mathbf{N}$ & $\%$ \\
\hline 1 a 2 dias por semana & 26 & $74 \%$ \\
\hline 3 a 4 dias por semana & 6 & $17 \%$ \\
\hline 4 a 5 dias por semana & 2 & $6 \%$ \\
\hline 6 dias por semana & 1 & $3 \%$ \\
\hline Total & 35 & $100 \%$ \\
\hline
\end{tabular}

Tabela 11. Frequência semanal que os aprendizes jogavam o PortuglishQuizlet. Fonte: Os autores.

Perguntou-se ainda se o Portuglish Quizlet causou algum impacto na aprendizagem de inglês: a maioria respondeu que se beneficiou com o uso do PortuglishQuizlet, como pode ser visto na Tabela 12:

\begin{tabular}{ccc}
\hline Opções & N & $\%$ \\
\hline Sim & 28 & $80 \%$ \\
Não & 07 & $20 \%$ \\
\hline Total & 35 & $100 \%$ \\
\hline
\end{tabular}

Tabela 12. Impacto do Portuglish Quizlet na aprendizagem na disciplina de Inglês.

Fonte: Os autores.

Perguntamos também quais foram as dificuldades encontradas: eles falaram da questão do tempo para responder e identificar as classes presentes no jogo. Na questão seguinte, indagou-se o que mudariam no jogo: entre as respostas mais citadas, destacamos acrescentar mais informações; não apagasse o que era feito; que fosse menos repetitivo; acrescentar mais palavras e um mecanismo que fosse possivel falar, como no aplicativo Duolingo. A questão a seguir indagou se os alunos indicariam o jogo para outro colega jogar: a maioria respondeu que indicaria, de acordo com o apresentado na Tabela 13:

\begin{tabular}{ccc}
\hline Opções & $\mathbf{N}$ & $\%$ \\
\hline Sim & 33 & $94 \%$ \\
Não & 02 & $6 \%$ \\
\hline Total & 35 & $100 \%$
\end{tabular}

Tabela 13. Recomendação do PortuglishQuizlet aos colegas.

Fonte: Os autores.

LínguaTec, Instituto Federal de Educação, Ciência e Tecnologia do Rio Grande do Sul, Bento Gonçalves 
Os dados apresentados aparentam mostrar que os alunos estão cientes dos benefícios decorrentes do estudo de uma LE, embora $86 \%$ dos participantes nunca tenham feito um curso de inglês e apenas $46 \%$ deles consideram esse idioma importante para sua formação acadêmica. 0 PortuglishQuizlet parece ter sido bem aceito pelos participantes, visto que $60 \%$ deles relataram que gostavam de jogar devido a sua intuitividade e que aprenderam novas palavras. Ademais, $80 \%$ afirmaram que se beneficiaram com o uso da ferramenta, a classificaram como positiva para 0 aprendizado e afirmaram que indicariam o jogo para outro colega, uma vez que o jogo testa os conhecimentos deles sobre as classes gramaticais e auxilia na aprendizagem de inglês. Na próxima seção, apresentaremos nossas Considerações Finais sobre o PortuglishQuizlet.

\section{0 fim de um ciclo é sempre uma oportunidade de crescimento!}

O PortuglishQuizlet foi desenvolvido como uma intervenção ao problema de trabalhar as classes gramaticais do inglês, uma dificuldade oriunda da compreensão superficial que os discentes têm sobre as classes gramaticais do português. Os resultados encontrados, apresentados na seção anterior, deram a impressão à docente responsável pela aplicação da proposta, uma das autoras deste artigo, que os alunos pareciam ter compreendido a distinção entre "palavras de conteúdo" e "palavras de função" com o auxílio do jogo, o que dialoga com os argumentos de Costa e Lima (2014), quando os autores asseveram que jogos educacionais promovem mais interesse por parte dos educandos. Os resultados também parecem corroborar com o que afirma Melo (2005), sobre como um jogo pode contribuir significantemente para o processo de construção do conhecimento dos discentes.

Desenvolver um jogo educacional para auxiliar na aprendizagem de inglês em um dos campi do interior do estado do IFCE era o objetivo geral da experiência ora relatada. Uma vez que a maioria dos participantes informou que o uso da ferramenta viabilizou a aprendizagem da língua inglesa, podemos concluir que o ensino de inglês com o auxílio do PortuglishQuizlet parece ter beneficiado os discentes. Acreditamos que a falta de conhecimento teórico acerca da língua portuguesa dificulta o processo de aprendizagem dos discentes das disciplinas de "Inglês Instrumental", "Inglês Instrumental l" e "Inglês Técnico". Pouca familiaridade com uma determinada língua parece causar desinteresse nos aprendizes. Com tal projeto, podemos concluir que o PortuglishQuizlet foi bem aceito pelos estudantes, embora a amostra seja relativamente pequena, e que seu uso como apoio às atividades que ocorrem em sala pode ser viável. No PortuglishQuizlet, a língua é estudada apenas no nível lexical, de uma forma 
descontextualizada. Todavia, considerando a base de conhecimentos em inglês (e em português) da maioria dos discentes, cremos que, independentemente do que seja, os conhecimentos aprendidos são positivos.

Para termos dados mais robustos, faz-se necessária a aplicação desse jogo como prática de ensino em um número maior de turmas. Vislumbramos ainda a possibilidade de reformulação do jogo, envolvendo outras classes gramaticais, focando ainda no desenvolvimento do conhecimento teórico sobre o português. Portanto, pesquisas futuras, que analisem uma possível relação entre o desempenho acadêmico dos discentes e a performance deles no PortuglishQuizlet deverão ser conduzidas. Futuramente, deseja-se que o jogo seja utilizado por professores e alunos de outros campi. Espera-se que o PortuglishQuizlet possa se tornar um aliado para os usuários estudarem inglês e que contribua para aprofundar conhecimentos básicos nessa língua.

\section{REFERÊNCIAS}

ALVES, F. Gamification: como criar experiências de aprendizagem engajadoras: um guia completo: do conceito à prática. 2 ed. São Paulo: DVS Editora, 2014.

BARBANTI, V. J. Dicionário de Educação Física e Esporte. $2^{a}$ Edição. Barueri - SP: Editora Manole, 2003.

COSTA, É. da S.; LIMA, P. L. S. Playing and Learning (Jogando e Aprendendo): Jogos didáticos no processo de ensino-aprendizagem da Língua Inglesa. Revista Episteme Transversalis. V. 7, N. 2, 2014. Disponível em: http://www.ugb.edu.br/revista-episteme-transversalis/edicao_7/ARTIG05.pdf. Acesso em: 12 mai. 2020.

CRESPO, N. D. de O.; CRESPO, L. C. (Org.). Ferramentas Digitais para o Ensino: O Ensino Remoto Emergencial em Evidência - 1. ed. - Recife: Even3 Publicações, 2020.

ENGLISHCLUB.COM. 100 Most Common Words. Disponível em: https://www.englishclub.com/vocabulary/common-words-100.htm. Acesso em 07 jan. 2020.

FRANCO, B. A. da R. Língua inglesa e tecnologia: o uso do Quizlet em sala de aula. Revista CBTecLE. v. 1, n. 2, 2018. Disponível em: https://revista.cbtecle.com.br/index.php/CBTecLE/article/view/148. Acesso em: 12 out. 2021.

KISHIMOTO, T. M. Jogo, brinquedo, brincadeira e a educação. São Paulo: Cortez, 1996.

MELO, C. M. R. As atividades lúdicas são fundamentais para subsidiar ao processo de construção do conhecimento (continuação). Información Filosófica. v. 2, nº 1, p.128- 137, 2005. 
METROPOLY. A história do UNO, o clássico jogo do baralho colorido! 4 de outubro de 2017. Disponível em: https://www.metropolybar.com.br/a-historia-do-uno-o-classico-jogo-do-baralho-coloridol. Acesso em 27 out. 2021.

PAIVA, V. L. M. de O. e. Manual de pesquisa em estudos linguísticos. São Paulo: Parábola, 2019.

QUIZLET INC. Quizlet, 2020. Portuglish. Disponivel em: https://quizlet.com/br/573399467/portuglishflash-cards/?new. Acesso em 07 jan. 2020.

SILVA, S. Dinâmicas e jogos para aulas de idiomas. Petrópolis, RJ: Vozes, 2012.

SOUSA, F. M. de. Considerações sobre o processo de ensino/aprendizagem de pronúncia em língua inglesa. Meu Artigo. Brasil Escola. Disponível em: https://meuartigo.brasilescola.uol.com.br/ingles/consideracoes-sobre-processo-ensino-aprendizagempronuncia-.htm. Acesso em: 12 mai. 2020

YIN, R. K. Estudo de caso: planejamento e métodos. 2.ed. Porto Alegre, RS: Bookman, 2001.

Data de submissão: 26/09/2021. Data de aprovação: 04/11/2021. 